\title{
EFEITO DO ENSACAMENTO NA QUALIDADE DOS FRUTOS E NA INCIDÊNCIA DA BROCA-DOS-FRUTOS DA ATEMOIEIRA E DA PINHEIRA $\left({ }^{1}\right)$
}

\author{
MARLON CRISTIAN TOLEDO PEREIRA $\left({ }^{2 *}\right)$; NILCEU BANDEIRA $\left({ }^{3}\right)$; \\ ROBERTO CÉLIO ANTUNES JÚNIOR $\left({ }^{3}\right)$; SILVIA NIETSCHE $\left({ }^{2}\right)$; MANOEL XAVIER \\ DE OLIVEIRA JÚNIOR $\left({ }^{3}\right)$; CLARICE DINIZ ALVARENGA $\left({ }^{2}\right)$; TELMA MIRANDA \\ DOS SANTOS $\left({ }^{3}\right)$; JANAÍNA RIBEIRO OLIVEIRA $\left({ }^{3}\right)$
}

\begin{abstract}
RESUMO
Este estudo teve por objetivo avaliar o uso de diferentes invólucros nos frutos de atemoieira e pinheira na qualidade físico-química dos frutos e na incidência da broca-dos-frutos, Cerconota anonella. Os experimentos foram instalados em dois pomares comerciais: um de atemoieira no município de Matias Cardoso e outro de pinheira no município de Verdelândia, Norte de Minas Gerais. Os tratamentos para a atemoieira consistiram em: 1) Testemunha (sem ensacamento); 2) Saco plástico leitoso; 3) Saco de TNT (tecido-não-tecido) branco sem fundo e 4 ) Saco de TNT branco com fundo. Para a pinheira foi modificado apenas o tratamento 2 para saco de papel pardo. Avaliaram-se número de dias da polinização à colheita, número de dias da colheita ao amadurecimento, ocorrência de injúrias e brocas e características físico-químicas dos frutos. Observam-se maior número de dias entre a colheita e o amadurecimento e mais firmeza nos frutos de pinheira não-ensacados. O uso do plástico leitoso controlou a broca em frutos de atemoieira. As características físico-químicas: massa, comprimento, diâmetro dos frutos e teor de sólidos solúveis totais da polpa não foram influenciados pelo uso dos invólucros.
\end{abstract}

Palavras-chave: Annona squamosa x Annona cherimolia, Cerconota anonella, invólucros, qualidade físicoquímica.

\section{ABSTRACT \\ BAGGING EFFECT UPON EITHER QUALITY OF THE FRUITS AND INCIDENCE OF THE FRUIT BORER IN ATEMOYA AND SWEETSOP}

\begin{abstract}
This study was conducted to evaluate the effect from using different involucres for fruits of the atemoya and sweetsop upon either physiochemical quality of the fruits and incidence of the fruit borer Cerconota anonella. The experiments were set up in two commercial orchards: one with atemoya at Matias Cardoso county and the other one with sweetsop at Verdelândia on northern Minas Gerais state. The treatments for atemoya consisted of: 1) Control (without bagging); 2) Milky plastic bag; 3) White, bottomless, tissue-non-tissue (TNT) bag; and (4) With bottom TNT bag. For the sweetsop, only treatment 2 was modified to brown paper bag. The following evaluation were performed: the number of days from pollination to harvest, number of days from harvest to ripening, occurrence of injuries and borers, and the physiochemical characteristics of the fruits. The no-bagged sweetsop fruits showed higher number of days between the harvest and ripening and higher firmness. The use of the milky plastic controlled the borer in atemoya fruits. The following physiochemical characteristics were not affected by the use of those involucres: weight, length, fruit diameters, and the content of the total soluble solids in the pulp.
\end{abstract}

Key words: Annona squamosa x Annona cherimolia, Cerconota anonella, involucres, physiochemical quality.

$\left({ }^{1}\right)$ Recebido para publicação em 11 de julho de 2007 e aceite em 22 de dezembro de 2008.

( $\left.{ }^{2}\right)$ Departamento de Ciências Agrárias, Curso de Agronomia, UNIMONTES, Caixa Postal 91, 39440-000 Janaúba (MG). E-mail: marlon.pereira@unimontes.br $\left(^{*}\right)$ Autor correspondente; clarice.corsato@unimontes.br

$\left({ }^{3}\right)$ Curso de Agronomia da UNIMONTES, Caixa Postal 91, 39440-000. Janaúba (MG). Bolsista de Iniciação Científica da FAPEMIG. E-mail: janainaribeiro84@yahoo.com.br. 


\section{INTRODUÇÃO}

A cadeia produtiva da fruticultura na Região Norte mineira é uma importante atividade econômica e social, gerando renda aos pequenos produtores e empregos à população. $\mathrm{O}$ crescimento da agricultura irrigada no Norte de Minas Gerais, desde o início da década de 90, foi facilitado tanto pelas condições edafoclimáticas locais, quanto pela disponibilidade de crédito e melhoria da infraestrutura do agronegócio. Esse fato permitiu a expansão da área cultivada com diferentes espécies frutíferas e o aprimoramento das tecnologias aplicadas à produção e pós-colheita (BORBOREMA, 2003).

No Brasil, toda a área plantada com anonáceas soma 10.500 hectares, dos quais 7.100 ficam na Bahia, ficando o Estado de Pernambuco e Alagoas como segundo e terceiro maiores produtores (IbGE, 2005). Na comercialização das anonáceas na Ceagesp, São Paulo, Bahia e Minas Gerais são os principais fornecedores. Conforme os dados analisados, em 2005, o predomínio da comercialização da pinha foi de $57 \%$ e o da atemóia, de $36 \%$, com oferta das frutas durante o ano todo. O mercado da pinha é abastecido principalmente por Bahia (52\%) e São Paulo (26\%). Para a atemóia, a Ceagesp recebe os maiores volumes de São Paulo e Minas Gerais, com $47 \%$ e $37 \%$ respectivamente (NogUeIRA et al., 2007).

A carência de variedades melhoradas e o pequeno conhecimento sobre os problemas fitossanitários, têm limitado o cultivo destas anonáceas (Granadino e CAVE, 1994). Dentre os problemas fitossanitários, merecem destaque as pragas do complexo Bephratelloides sp. (Hymenoptera: Eurytomidae) e a espécie Cerconota anonella (Lepidóptera: Oecophoridae), as quais vêm desestimulando e limitando o estabelecimento de novos plantios comerciais no país (Melo et al., 1983; JUNQUEIRA et al., 1996).

A broca-do-fruto, C. anonella, é considerada uma das pragas mais sérias do gênero Annona spp. Os danos expressivos causados aos frutos são caracterizados pelo apodrecimento da polpa e, externamente, a parte atacada torna-se endurecida e enegrecida, reduzindo seu valor comercial, tornandoos impróprios para a comercialização in natura ou para o processamento industrial (SÃo José et al., 1997; Icuma, 2003; Martelleto, 1997; Morales e Manica, 1994). Aliado a esses fatores, quando o ataque ocorre em frutos novos, resulta em sua queda prematura (GALLO et al., 2002).

Várias medidas são recomendadas para o controle da broca-do-fruto, sendo o uso de produtos químicos, ainda, o principal método. Entretanto, embora este seja menos oneroso ao produtor, os prejuízos causados ao meio ambiente e à saúde humana são muito severos (CARVALHO et al., 2000; MANiCA, 2003). Uma das técnicas aplicadas para proteger os frutos de anonáceas contra o ataque de insetos-praga é o ensacamento dos frutos com diferentes materiais (Villalobos, 1987; Carneiro e BEZERRIL, 1993; NiETSCHE et al., 2004).

O ensacamento dos frutos é considerado uma das práticas fitossanitárias mais antigas e eficazes, mas com o surgimento dos inseticidas e a redução da mão-de-obra familiar foi sendo substituído gradualmente (LiPP e SECCHI, 2002). Entretanto, com a mudança no perfil do consumidor, particularmente os de fruta 'in natura', tem sido aumentada a exigência por alimentos com níveis reduzidos, ou mesmo isentos, de resíduos agrotóxicos. Desta forma, o aprimoramento da técnica do ensacamento dos frutos tem merecido destaque nos estudos para controle de pragas em fruteiras (CARVALHO et al., 2000).

Inúmeras espécies de fruteiras permitem o ensacamento, como por exemplo, pêssego, nêspera, ameixa, uva, pêra, goiaba, banana, tomate, graviola, dentre outras (ALVES, 2000, JORDÃO e NAKANO, 2000, Sacramento, 2002, Piza Júnior e Kavati, 2002, Rosa, 2002). Dentre as espécies de importância econômica que pertencem à família Anonaceae, são raros os relatos na literatura sobre metodologias de ensacamento de frutos de pinheira e atemoieira, entretanto, em vários estudos constata-se a eficiência desse método na prevenção do ataque de pragas em graviola, sendo testados diversos tipos de invólucros na proteção dos frutos (MCCOMIE, 1987; CARNEIRO e BeZerRil, 1993; Broglio-Micheletti et al., 2001, Manica, 2003) e, em alguns casos, há associação com inseticidas para o aumento da eficiência do método (Villalobos, 1987).

O objetivo deste trabalho foi avaliar o efeito de diferentes invólucros para o ensacamento de frutos de atemoieira e pinheira, na qualidade físico-química e na redução da incidência da broca-dos-frutos.

\section{MATERIAL E MÉTODOS}

Os experimentos foram desenvolvidos em duas propriedades situadas no Norte do Estado de Minas Gerais: Sítio Guanabara, na gleba C2, lote 38 M, do Projeto Jaíba, no município de Matias Cardoso, MG, utilizando atemoieira 'Gefner', sob espaçamento de $4 \mathrm{~m} \times 2 \mathrm{~m}$ e Fazenda Nova Canaã no município de Verdelândia, MG, em pomar de pinheira implantado com mudas oriundas de sementes, sob espaçamento de $3 \mathrm{~m} \times 2 \mathrm{~m}$. O clima da região é do tipo Aw, segundo a classificação de Koppen, médias 
anuais de precipitação pluvial de $900 \mathrm{~mm}$, temperatura média de $25{ }^{\circ} \mathrm{C}$ e umidade relativa do ar de $56 \%$.

Nas duas propriedades foram selecionadas 20 plantas dispostas em duas fileiras na parte central do pomar. As flores foram polinizadas artificialmente por meio do uso de grãos de pólen de pinheira para atemoieira e para a pinheira. O ensacamento dos frutos foi realizado aproximadamente cinco semanas após a polinização artificial, quando os frutos atingiram comprimento de $3 \mathrm{~cm}$ e já era possível definir se o fruto não seria deformado.

Nos dois experimentos, utilizou-se o delineamento experimental em blocos casualizados com quatro tratamentos e cinco repetições. Cada bloco foi composto por quatro plantas e em cada planta foram coletados, aleatoriamente, quatro frutos, sendo um fruto para cada tratamento. A parcela experimental foi composta por quatro frutos de cada tratamento nas quatro plantas de cada repetição. Para a atemoieira, os tratamentos consistiram em: 1) testemunha sem invólucro; 2) saco plástico leitoso (30 cm x 20,6 cm);3) saco de TNT (tecido-não-tecido) branco sem fundo e 4) saco de TNT branco com fundo. Para a pinheira os tratamentos consistiram em: 1) testemunha sem invólucro; 2) saco de papel pardo (2 kg; $27 \mathrm{~cm} \times 19 \mathrm{~cm})$; 3) saco de TNT (tecido-não-tecido) branco sem fundo e 4) saco de TNT branco com fundo. Os sacos de TNT mediam $28 \mathrm{~cm} \times 21 \mathrm{~cm}$. A colheita da atemoieira foi iniciada a partir de 13/1/2006, com 125 dias após a polinização artificial, e a da pinheira foi realizada aos 97 dias após a polinização, em 27/1/2006.

As avaliações foram realizadas no Laboratório de Fisiologia Pós-colheita da Universidade Estadual de Montes Claros, no Campus de Janaúba (MG).

As características avaliadas para as duas espécies foram as seguintes: comprimento, diâmetro e massa de fruto; injúrias (porcentagem de danos mecânicos e/ou queima de frutos por insolação, obtida por meio de avaliação visual realizada em cada fruto); incidência de brocas (porcentagem dos frutos com presença de pelo menos uma broca); número de dias da colheita ao amadurecimento; firmeza dos frutos (medidas tomadas em três partes do fruto utilizandose penetrômetro de mão); massa da casca, polpa e sementes; número de sementes; teor de sólidos solúveis totais; perda de massa; porcentagem de polpa; número de sementes por 100 gramas de polpa. Para a atemóia foi ainda avaliado o número de dias da polinização à colheita,

Os dados foram submetidos à análise de variância. Quando constatada a significância pelo Teste F, o efeito dos tratamentos foi submetido ao Teste
Tukey, ao nível de 5\% de probabilidade. As análises foram realizadas por meio do programa Sistema de Análises Estatísticas e Genética- SAEG, da Universidade Federal de Viçosa (RIBEIRo JúnIor, 2001).

\section{RESULTADOS E DISCUSSÃO}

\section{Atemoieira}

Os tratamentos testados não influenciaram as características: número de dias da polinização à colheita, comprimento, diâmetro, massa do fruto, injúrias, número de dias da colheita ao amadurecimento, firmeza, massa da casca, da polpa e de sementes, teor de sólidos solúveis totais, porcentagem de perda de massa após colheita, massa do fruto maduro, porcentagem de polpa e número de sementes por 100 gramas de polpa (Tabelas 1, 2 e 3). Por esses resultados, nota-se que o uso dos invólucros não prejudicou a maioria dos atributos físico-químicos dos frutos de atemoieira. Estudos desenvolvidos por Broglio-Micheletti e Berti-Filho (2000), objetivando o controle da Cerconota anonella em graviola, por meio do ensacamento com diferentes invólucros, obtiveram em torno de $91 \%$ de frutos colhidos sem danos causados por fatores bióticos e abióticos, quando foram ensacados com sacos plásticos microperfurados.

Por outro lado, em frutos ensacados com saco plástico leitoso não ocorreu ataque de brocas, diferindo do uso de sacos de TNT branco sem fundo, com média aproximada de $33 \%$ de frutos brocados (Tabela 1). A testemunha (frutos sem ensacamento) e o tratamento com TNT branco com fundo tiveram cerca de $20 \%$ de frutos com broca. Observou-se que ocorreu a maior média de frutos brocados no ensacamento com TNT branco sem fundo, e pode estar relacionada ao fato de o adulto da $C$. anonella ter alcançado o fruto pela parte inferior do saco de TNT. BROGLIO-MicheLETTI et al. (2001) obtiveram resultados semelhantes quando utilizaram diferentes invólucros no controle de $C$. anonella em gravioleiras.

Os melhores resultados foram notados quando utilizaram sacos plásticos fechados. No caso dos sacos abertos ou perfurados os resultados dos autores não diferiram daqueles obtidos na testemunha (sem proteção), o que pode sugerir que as mariposas procuram algum orifício no invólucro para efetuar a postura; entretanto, no momento da colheita dos frutos, não foram observados invólucros rasgados. 
Tabela 1. Número de dias da polinização a colheita (NDPC), comprimento (Comp), diâmetro (Diam) e massa do fruto (PFru), porcentagem de injúria (Inju), porcentagem de frutos brocados (BFru) de atemóia 'Gefner', submetida a diferentes invólucros, cultivada no município de Matias Cardoso, Norte de Minas Gerais, setembro de 2005 a fevereiro de 2006

\begin{tabular}{|c|c|c|c|c|c|c|}
\hline Tratamentos & NDPC & Comp & Diam & PFru & Inju & BFru \\
\hline & dias & \multicolumn{2}{|c|}{$\mathrm{cm}$} & $\mathrm{g}$ & 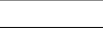 & 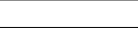 \\
\hline Testemunha & $125,8 \mathrm{~A}$ & $8,9 \mathrm{~A}$ & $7,6 \mathrm{~A}$ & $304,0 \mathrm{~A}$ & $3,0 \mathrm{~A}$ & 23,3 A B \\
\hline Plástico leitoso & $125,5 \mathrm{~A}$ & $9,0 \mathrm{~A}$ & $7,6 \mathrm{~A}$ & $292,9 \mathrm{~A}$ & $0,0 \mathrm{~A}$ & $0,0 \mathrm{~B}$ \\
\hline TNT branco s/ fundo & $125,8 \mathrm{~A}$ & $8,8 \mathrm{~A}$ & $7,9 \mathrm{~A}$ & $321,7 \mathrm{~A}$ & $0,3 \mathrm{~A}$ & $33,3 \mathrm{~A}$ \\
\hline TNT branco c/ fundo & $125,8 \mathrm{~A}$ & $9,1 \mathrm{~A}$ & $8,2 \mathrm{~A}$ & $360,3 \mathrm{~A}$ & $0,5 \mathrm{~A}$ & $18,3 \mathrm{~A} \mathrm{~B}$ \\
\hline CV (\%) & 1,0 & 5,6 & 7,5 & 15,6 & 246,1 & 87,6 \\
\hline
\end{tabular}

Médias seguidas da mesma letra na coluna não diferem significativamente, a 5\% de probabilidade, pelo teste de Tukey.

Tabela 2. Número de dias da colheita ao amadurecimento (NDCA), firmeza do fruto (Firm), massa da casca (MCas), massa da polpa (MPos), massa de sementes (MSem), número de sementes (NSem) de atemóia 'Gefner', submetida a diferentes invólucros, cultivada no município de Matias Cardoso, Norte de Minas Gerais, janeiro a fevereiro de 2006

\begin{tabular}{|c|c|c|c|c|c|c|}
\hline Tratamentos & NDCA & Firm & PCas & PPol & PSem & NSem \\
\hline & dias & $\mathrm{Kgf} / \mathrm{cm}^{2}$ & 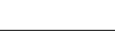 & $-\mathrm{g}$ & 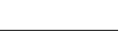 & ud \\
\hline Testemunha & $8,4 \mathrm{~A}$ & $3,6 \mathrm{~A}$ & $63,1 \mathrm{~A}$ & $148,6 \mathrm{~A}$ & $19,4 \mathrm{~A}$ & $47,5 \mathrm{AB}$ \\
\hline Plástico leitoso & $7,8 \mathrm{~A}$ & $4,0 \mathrm{~A}$ & $61,0 \mathrm{~A}$ & $132,8 \mathrm{~A}$ & $24,1 \mathrm{~A}$ & $39,2 \mathrm{~B}$ \\
\hline TNT branco s/ fundo & $7,4 \mathrm{~A}$ & $3,8 \mathrm{~A}$ & $69,0 \mathrm{~A}$ & $155,9 \mathrm{~A}$ & $21,1 \mathrm{~A}$ & $45,1 \mathrm{AB}$ \\
\hline TNT branco c/ fundo & $6,9 \mathrm{~A}$ & $3,6 \mathrm{~A}$ & $80,2 \mathrm{~A}$ & $169,9 \mathrm{~A}$ & $23,4 \mathrm{~A}$ & $53,9 \mathrm{~A}$ \\
\hline $\mathrm{CV}(\%)$ & 18,2 & 17,1 & 26,4 & 14,5 & 37,4 & 16,8 \\
\hline
\end{tabular}

Médias seguidas da mesma letra na coluna não diferem significativamente, a 5\% de probabilidade, pelo teste de Tukey.

Tabela 3. Teor de sólidos solúveis totais (SST), perda de massa (PMassa, massa do fruto maduro (MFMad), porcentagem de polpa (PPolpa) e número de sementes/100g de polpa de atemóia 'Gefner', submetida a diferentes invólucros, cultivada no município de Matias Cardoso, Norte de Minas Gerais, no período de janeiro a fevereiro de 2006

\begin{tabular}{lccccc}
\hline Tratamentos & SST & PMassa & PFMad & PPolpa & Sementes /100 g Polpa \\
\hline & ${ }^{\circ}$ Brix & $\%$ & $\mathrm{~g}$ & $\%$ & $\mathrm{n}^{\circ}$ \\
Testemunha & $28,7 \mathrm{~A}$ & $23,7 \mathrm{~A}$ & $231,1 \mathrm{~A}$ & $64,3 \mathrm{~A}$ & $34,0 \mathrm{~A}$ \\
Plástico leitoso & $30,4 \mathrm{~A}$ & $25,9 \mathrm{~A}$ & $217,9 \mathrm{~A}$ & $61,0 \mathrm{~A}$ & $29,5 \mathrm{~A}$ \\
TNT branco s/ fundo & $29,9 \mathrm{~A}$ & $23,0 \mathrm{~A}$ & $245,6 \mathrm{~A}$ & $64,0 \mathrm{~A}$ & $29,0 \mathrm{~A}$ \\
TNT branco c/ fundo & $30,3 \mathrm{~A}$ & $24,1 \mathrm{~A}$ & $273,4 \mathrm{~A}$ & $62,1 \mathrm{~A}$ & $32,0 \mathrm{~A}$ \\
\hline CV $(\%)$ & 4,7 & 13,9 & 15,1 & 14,5 & 16,8 \\
\hline
\end{tabular}

Médias seguidas da mesma letra na coluna, não diferem significativamente a 5\% de probabilidade, pelo teste de Tukey.

Outro fator a ser considerado é a oviposição na fase anterior ao ensacamento dos frutos, pois, segundo FENNAH (1937), as posturas podem ocorrer nas brotações e inflorescências, na ausência de fruto ou em alta infestação da praga, o que justifica controle preventivo nesta fase, caso haja presença dos adultos na área. Embora as plantas tenham recebido pulverizações preventivas, o controle químico pode não ter sido efetivo, visto que segundo BONAVENTURE
(1999), a presença de um adulto na armadilha luminosa justifica o início do controle químico.

Embora não tenha havido diferença estatística, na testemunha constataram-se 3\% de frutos com presença de injúrias, enquanto nos demais tratamentos houve no máximo $0,5 \%$ de frutos com injúrias (Tabela 1). Embora a característica de intensidade de coloração dos 
frutos não tenha sido avaliada, não foram observados efeitos de descoloração nos frutos ensacados. Estudos realizados por BroglioMicheleti et al. (2001), avaliando o efeito de diferentes invólucros na graviola, observaram que os frutos ensacados com papel tipo Kraft tenderam a produzir frutos de coloração mais amarelada. Entretanto, na cultura da goiaba o ensacamento dos frutos com papel manteiga, além de controlar a mosca-das-frutas e o gorgulho, melhoram a coloração dos frutos, tornando-os mais atrativos ao consumo in natura (JUNQUEIRA et al., 1980). Os frutos de atemoieira são muito sensíveis em pré e póscolheita. O atrito de frutos com folhas, galhos e outros frutos pela ação do vento pode depreciá-los no momento da comercialização, além da exposição aos insetos e outros agentes que possam causar algum dano aos frutos. Para tanto, o uso de invólucros que auxiliem na proteção das características físicas dos frutos é considerada prática importante para garantir maiores preços na comercialização de seus produtos. No entanto, a relação custo/beneficio da utilização de invólucros em frutos de atemoieira deve ser analisada.

Nos frutos ensacados com TNT com fundo, observou-se maior número de sementes, comparado aos frutos ensacados com saco plástico leitoso (Tabela 2). Não há relatos na literatura de que o ensacamento com TNT favoreça o incremento do número de sementes em frutos de anonáceas. Em estudos realizados por Ostapiv et al. (2006) na videira cultivar Vênus, verificou-se que nos cachos ensacados com sacos de polipropileno microperfurado, o aumento do número médio de bagas por cacho foi significativo. De acordo com Kavati (1997), o número de sementes nas espécies da família Anonaceae está relacionado com o número de carpelos polinizados por flor.

\section{Pinheira}

Os tratamentos testados não influenciaram as características comprimento, diâmetro e massa dos frutos, injúrias, broca do fruto, massa da casca, da polpa, de sementes, número de sementes, teor de sólidos solúveis totais, porcentagem de perda de massa após colheita, massa do fruto maduro, porcentagem de polpa e número de sementes por 100 gramas de polpa (Tabelas 4, 5 e 6). O resultado indica que o uso de diferentes invólucros não prejudicou a maioria dos atributos físico-químicos dos frutos de pinheira.

Observou-se que o número de dias da colheita ao amadurecimento foi significativamente menor para frutos ensacados com TNT em relação à testemunha (Tabela 4). Na videira cultivar Vênus, em cachos ensacados com sacos de polipropileno também ocorreu maior velocidade de maturação após a colheita (OSTAPIV et al., 2006). O amadurecimento mais demorado dos frutos não ensacados pode ter ocorrido devido à maior ação de fatores ambientais na casca desses frutos sem ensacamento, tornando sua epiderme mais resistente, grossa e rugosa; esse fato pode ter proporcionado redução da respiração do fruto em pós-colheita e aumentado o período até o amadurecimento.

Apesar da diferença não ser significativa em relação ao saco de papel, nos frutos de pinheira não ensacados observou-se maior resistência em póscolheita, demonstrada pela maior firmeza quando comparados com os protegidos por TNT (Tabela 5). Em trabalhos realizados por FAORO (2003), demonstrouse que o ensacamento de frutos de pera Japonesa resultou na obtenção de frutos com uma película mais lisa, livre de doenças e pragas, e que a alta umidade, provavelmente, é o maior agente causal da rugosidade dos frutos. Existe correlação entre a rugosidade e o número de horas de exposição à alta umidade e à precipitação pluvial, especialmente entre o $16 .^{\circ}$ e $20 .^{\circ}$ dia após a plena floração.

Tabela 4. Comprimento (Comp), diâmetro (Diam) e massa do fruto (MFru), porcentagem de injúria (Inju), porcentagem de frutos brocados (BFru) e número de dias da colheita ao amadurecimento (NDCA) de pinha, submetida a diferentes invólucros, cultivada no município de Verdelândia, Norte de Minas Gerais, janeiro a fevereiro de 2006

\begin{tabular}{|c|c|c|c|c|c|c|}
\hline Tratamento & Comp & Diam & PFru & Inju & BFru & NDCA \\
\hline & \multicolumn{2}{|c|}{$\mathrm{cm}$} & $\mathrm{g}$ & \multicolumn{2}{|c|}{$\%$} & dias \\
\hline Testemunha & $9,1 \mathrm{~A}$ & $8,3 \mathrm{~A}$ & $324,2 \mathrm{~A}$ & $14,2 \mathrm{~A}$ & $10,0 \mathrm{~A}$ & $6,7 \mathrm{~A}$ \\
\hline Papel & $8,8 \mathrm{~A}$ & $8,4 \mathrm{~A}$ & $311,5 \mathrm{~A}$ & $7,2 \mathrm{~A}$ & $11,7 \mathrm{~A}$ & 5,9 A B \\
\hline TNT branco s/ fundo & $8,9 \mathrm{~A}$ & $8,3 \mathrm{~A}$ & $312,2 \mathrm{~A}$ & $10,0 \mathrm{~A}$ & $5,0 \mathrm{~A}$ & $5,4 \mathrm{~B}$ \\
\hline TNT branco c/ fundo & $8,7 \mathrm{~A}$ & $8,3 \mathrm{~A}$ & $305,3 \mathrm{~A}$ & $10,0 \mathrm{~A}$ & $10,0 \mathrm{~A}$ & $5,3 \mathrm{~B}$ \\
\hline CV (\%) & 3,7 & 4,3 & 10,1 & 169,6 & 186,9 & 11,9 \\
\hline
\end{tabular}

Médias seguidas da mesma letra na coluna, não diferem significativamente a $5 \%$ de probabilidade, pelo teste de Tukey. 
Tabela 5. Firmeza do fruto (Firm), massa da casca (MCas), massa da polpa (MPol), massa de sementes (MSem), número de sementes (NSem), teor de sólidos solúveis totais (SST) de pinhas submetidas a diferentes invólucros, cultivada no município de Verdelândia, Norte de Minas Gerais. Fevereiro de 2006

\begin{tabular}{|c|c|c|c|c|c|c|}
\hline Tratamentos & Firm & PCas & PPol & PSem & NSem & SST \\
\hline & $\mathrm{kgf} / \mathrm{cm}^{2}$ & & $-\mathrm{g}$ & - & n. ${ }^{\circ}$ & ${ }^{\circ}$ Brix \\
\hline Testemunha & $2,9 \mathrm{~A}$ & $127,8 \mathrm{~A}$ & $79,0 \mathrm{~A}$ & $25,0 \mathrm{~A}$ & $57,2 \mathrm{~A}$ & $28,7 \mathrm{~A}$ \\
\hline Papel & $2,7 \mathrm{~A} B$ & $131,4 \mathrm{~A}$ & $86,0 \mathrm{~A}$ & $24,5 \mathrm{~A}$ & $55,5 \mathrm{~A}$ & $28,2 \mathrm{~A}$ \\
\hline TNT branco s/ fundo & 2,2 B & $120,3 \mathrm{~A}$ & $97,0 \mathrm{~A}$ & $24,1 \mathrm{~A}$ & $55,1 \mathrm{~A}$ & $27,4 \mathrm{~A}$ \\
\hline TNT branco c/ fundo & $2,2 \mathrm{~B}$ & $124,4 \mathrm{~A}$ & $91,4 \mathrm{~A}$ & $27,6 \mathrm{~A}$ & $58,1 \mathrm{~A}$ & $28,5 \mathrm{~A}$ \\
\hline $\mathrm{CV}(\%)$ & 12,0 & 13,4 & 19,5 & 19,0 & 11,6 & 3,4 \\
\hline
\end{tabular}

Médias seguidas da mesma letra na coluna, não diferem significativamente a 5\% de probabilidade, pelo teste de Tukey.

Tabela 6. Perda de massa (PMassa), massa do fruto maduro (MFMad), porcentagem de polpa (PPolpa) e número de sementes/100 g de polpa de pinha, submetidas a diferentes invólucros, cultivada no município de Verdelândia, Norte de Minas Gerais. Fevereiro de 2006

\begin{tabular}{lcccc}
\hline Tratamentos & PMassa & MFMad & PPolpa & Sementes /100 g Polpa \\
\hline & $\%$ & $\mathrm{~g}$ & $\%$ & $\mathrm{n}^{\circ}$ \\
Testemunha & $28,4 \mathrm{~A}$ & $231,6 \mathrm{~A}$ & $34,1 \mathrm{~A}$ & $72,3 \mathrm{~A}$ \\
Papel & $22,6 \mathrm{~A}$ & $241,9 \mathrm{~A}$ & $35,6 \mathrm{~A}$ & $64,5 \mathrm{~A}$ \\
TNT branco s/ fundo & $23,3 \mathrm{~A}$ & $241,4 \mathrm{~A}$ & $40,2 \mathrm{~A}$ & $56,8 \mathrm{~A}$ \\
TNT branco c/ fundo & $20,7 \mathrm{~A}$ & $243,4 \mathrm{~A}$ & $37,6 \mathrm{~A}$ & $63,6 \mathrm{~A}$ \\
\hline CV $(\%)$ & 23,4 & 14,7 & 19,5 & 11,6 \\
\hline
\end{tabular}

Médias seguidas da mesma letra na coluna, não diferem significativamente a 5\% de probabilidade, pelo teste de Tukey.

Nesse período, há intenso crescimento do fruto e, em conseqüência, ocorrem aberturas na cutícula, favorecendo a penetração da água até as células epidérmicas, que absorvem esta água e, por pressão de turgência, se rompem (MORTON, 1987). Assim, no caso da pera Japonesa, devido à oxidação de seu conteúdo celular, adquirem a coloração marrombronzeada e a característica da rugosidade (FAORO, 2003).

Não foram observadas diferenças significativas entre os tratamentos com relação ao ataque de broca-dos-frutos, com média de 9,2\% de frutos atacados (Tabela 4). Possivelmente, as mariposas ovipositaram antes do ensacamento. $\mathrm{Na}$ cultura da graviola, os frutos são ensacados com sacos plásticos translúcidos perfurados, quando atingem entre 3 e $5 \mathrm{~cm}$ de diâmetro; esta prática auxilia no controle das brocas e na melhoria da qualidade dos frutos (SACRAMENTO, 2002). Na cultura da maçã, o ensacamento dos frutos $\operatorname{com} 2 \mathrm{~cm}$ de diâmetro, com sacos de papel manteiga e polipropileno, foi eficaz no controle da mariposa oriental na cv. Suprema, reduzindo também o ataque da mosca-das-frutas na cultivar Royal Gala (SANTOS e WAMSER, 2006).
Não se detectaram diferenças significativas entre os tratamentos para a característica injúria dos frutos, entretanto na testemunha verificaram-s $14 \%$ dos frutos com injúria, $4 \%$ a mais do que os ensacados, demonstrando a importância da proteção dos frutos para a manutenção de sua qualidade (Tabela 4).

\section{CONCLUSÕES}

1. A maioria dos atributos físico-químicos dos frutos de atemoieira e pinheira não é influenciada pelo uso dos invólucros.

2. O plástico leitoso pode ser utilizado como invólucro para o controle do ataque de brocas em frutos de atemoieira;

3. O ensacamento dos frutos de pinheira promoveu aumento no número de dias entre a colheita e o amadurecimento e maior firmeza;

\section{AGRADECIMENTOS}

Os autores agradecem à Fundação de Amparo à Pesquisa do Estado de Minas Gerais - FAPEMIG, e ao Conselho Nacional de Desenvolvimento Cientifico 
e Tecnológico - CNPq, pelo apoio financeiro e pela concessão da bolsa.

\section{REFERÊNCIAS}

ALVES, E. J. A cultura da banana: aspectos técnicos, socioeconômicos e agroindustriais. Brasília: Embrapa-SPI/ Cruz das Almas: Embrapa-CNPMF, 2000. 585p.

BONAVENTURE, L. A cultura da cherimóia e de seu híbrido a atemóia. São Paulo: Nobel, 1999. 182 p.

BORBOREMA, M. D. Comercialização e mercado bananeiro atual e perspectivas. In: SIMPÓSIO BRASILEIRO SOBRE BANANICULTURA, 5., WORKSHOP DE GENOMA MUSA, 1., 2003, Paracatu, MG. Anais... Cruz das Almas: Nova Civilização, 2003. v.1, p.48-53.

BROGLIO-MICHELETTI, S.M.F.; BERTI-FILHO, E. Controle de Cerconota anonella em pomar de gravioleira (Annona muricata L). Scientia Agricola, Piracicaba, v.57, n. 3, p. 557-559, 2000.

BROGLIO-MICHELETTI, S.M.F.; AGRA, A. G. S de M.; BARBOSA, G. V.S.; GOMES, F.L. Controle de Cerconota anonella (Sepp.) (Lep.: Oecophoridae) e de Bephratelloides pomorum (fab.) (Hym.: Eurytomidae) em frutos de graviola (Annona muricata L.). Revista Brasileira de Fruticultura, Jaboticabal, v.23, n.3, p. 722-725, 2001.

CARNEIRO, J. S.; BEZERRIL, E. F. Controle das Brocas dos Frutos( Cerconota anonella) e das sementes(Bephratelloides spp) da graviola no Planalto de Ibiapaba, CE. Anais da Sociedade Entomológica do Brasil, Piracicaba, v.22, n.1, p. 155-160, 1993.

CARVALHO, R.S.; NASCIMENTO, A. S.;MATRANGOLO, W.J.R. Controle Biológico. In: MALAVASI, A. ZUCCHI, R. A. Moscas-das-frutas de importância econômica no Brasil: Conhecimento básico e aplicado. Ribeirão Preto: Holos, 2000. p.113-117.

CODEVASF. Relatório de fases produtivas, programa de fruticultura. 2003. Disponível em: <www.codevasf.org.br>. Acesso em julho de 2003.

FAORO, I.D. Técnica e custo para o ensacamento de frutos de pêra japonesa. Revista Brasileira de Fruticultura, Jaboticabal, v.25, n.2, p.339-340. 2003.

FENNAH, R.G. Lepidopterous pests of the soursop in Trinidad. Tropical Agriculture, New Delhi, v. 14, n.8, p.244-245, 1937.

GALLO, D.; NAKANO, O.; SILVEIRA NETO, S.; CARVALHO, R. P. L.; BAPTISTA, G. C.; BERTI FILHO, E.; PARRA, J. R. P.; ZUCCHI, R. A.; ALVES, S. B.; VENDRAMIM, J. D.; MARCHINI, L. C.; LOPES, J. R. S.; OMOTO, C. Entomologia Agrícola. Piracicaba: FEALQ, 2002. 920p.

GRANADINO, C.A.; CAVE, R.D. Inventário de artópodros y hongos patógenos de Annona spp. en cuatro localidades de Honduras. Turrialba, San Jose, v.44, n.3, p.129-139, 1994.

IBGE. Levantamento sistemático da produção agrícola. Disponível: http:/ / www.ibge.gov.br Acesso em: julho de 2005.
ICUMA, I.M. Pragas das anonáceas. In:.MANICA, I. Frutas Anonáceas: ata ou pinha, atemólia, cherimólia e graviola. Tecnologia de produção, pós-colheita e mercado. Porto Alegre: Cinco Continentes, 2003. 596p.

JORDÃO, L.A.; NAKANO, O. O controle de pragas dos frutos do tomateiro pelo ensacamento das pencas. Anais da Sociedade Entomológica do Brasil, Piracicaba, v.29, n.4, p.773-782, 2000.

JUNQUEIRA, W. R; PRATES H. S.; FALAGUASTA, V. P. Goiaba: uma fruta tropical. Casa da Agricultura, Campinas, v.2, n.5, p.24-27, 1980.

JUNQUEIRA, N.T.V.; CUNHA, M.M.; OLIVEIRA, M.A.S.; PINTO, A.C.Q. Graviola para a exportação: aspectos fitossanitários. Brasília: EMBRAPA/SPI, 1996. 67p. (Série Publicações Técnicas FRUPEX, 22).

KAVATI, R.; BUENO, S.C.S.; TOKUNAGA, T. A cultura da atemóia. Campinas: CATI, 1997. 22p.

LIPP, J.P.; SECCHI, V.A. Ensacamento de frutos: uma antiga prática ecológica para controle da mosca-das-frutas. Agroecologia e Desenvolvimento Rural Sustentável, Porto Alegre, v.3, n.4, p.53-58, 2002.

MANICA, I. Frutas Anonáceas: ata ou pinha, atemólia, cherimólia e graviola. Tecnologia de produção, pós-colheita e mercado. Cinco Continentes, Porto Alegre, 2003. 595p.

MARTELLETO, L.A.P. Situação atual e perspectivas de anonáceas no Estado do Rio de Janeiro. Vitória da Conquista, BA: DFZ/UESB, 1997,310 p

McCOMIE, L. D. The soursop (Annona muricata L) in Trinidad, its importance, pest and problems associated with pest control. Journal of the Agricultural Society of Trinidad and Tobago, Trinidad, v. 87, p 42-55, 1987.

MELO, G. S. de; GONZAGA NETO, L.; MOURA, R.J.M. Cultivo da gravioleira (Annona muricata L.). Recife: IPA, 1983. 4p. (Instruções técnicas do IPA, 13)

MORALES, C.F.; MANICA, I. Moléstias e pragas. In: Fruticultura: Cultivo das anonáceas: Ata, Cherimólia, Graviola. Porto Alegre: EVANGRAF, 1994. p.78-91.

MORTON J.F. Fruits of warm climates. Miami: Curtis F. Dowling, 1987. 505 p.

NIETSCHE, S.; DURÃES, N.N.; PEREIRA, M.C.T.; ROCHA, M.V.; SANTOS, F.A.; SANTOS F.S.; NUNES C.F.; CUNHA, L.M.V. Qualidade físico-química de frutos de pinheira ensacados. Unimontes Científica, Montes Claros, v.6, n.2, p.141-144, 2004.

NOGUEIRA, E. A.; MELLO, N. T. C.; CASER, D.V. Anonáceas: do Brasil império a atemóia. Frutas e Derivados. Disponível em: http:/ /www.ibraf.org.br/x-re/f-revista.html. Acesso em 9/2/2007.

OSTAPIV , F.; MAZARO, S.M.; DONAZZOLO, J.; CITADIN, A.; LINK, M.; GOUVÊA, A. Influência do ensacamento sobre a qualidade da uva 'Vênus'. Synergismus Scyentifica, Pato Branco, v. 1, p.64-69, 2006. 
PIZA JUNIOR, C.T; KAVATI, R. Goiaba de mesa (Psidium guajava L.). Disponível em: http://www.agrocas.com.br. Acesso em 27/11/2002.

RIBEIROJÚNIOR, J.I. Sistema de Análise Estatística e Genética. 5.ed. Viçosa: UFV. 2001.

ROSA, J.I. Ensacamento de frutos. Porto Alegre: EMATER/ RS, 2002. p.4. (Informativo DAT, 70)

SACRAMENTO, C.K. Graviola. CEPLAC, Jornal do CEPLAC Notícias, julho, 2000. Disponível em: http:// www.ceplac.org.br/graviola.htm. Acesso em 27/11/2002.

SANTOS, J.P.; WAMSER, A.F. Efeito do ensacamento de frutos sobre danos causados por fatores bióticos e abióticos em pomar orgânico de macieira. Revista Brasileira de Fruticultura, Jaboticabal, v.28, n.2, p.1-5, 2006.

SÃO JOSÉ, A. R.; SOUZA, I. V. B.; MORAIS, O. M., REBOUÇAS, T. N. H. Anonáceas: produção e mercado - pinha, graviola, atemóia e cherimóia. Vitória da Conquista: UESB, 1997. 310p.

VILLALOBOS, E. Use of endosulfan and polyethylene bags to control Bephrata sp. Ashmead, the Annona seed borer (Annona cherimoia). San Jose, 1987. 41p. Dissertação (Mestrado em Entomologia) - Universidad Nacional de Costa Rica, San Jose. 